\title{
Correlation between intakes of carbohydrates, protein, and fat with random blood sugar levels in menopausal women
}

Original article

Ni Wayan Suniyadewia,", G.N Indraguna Pinatih ${ }^{\mathrm{b}}$

aNursing Department, STIKES Wira Medika Bali, Denpasar, Bali 80239, Indonesia

${ }^{b}$ Biomedical Department, Udayana University, Denpasar, Bali 80234, Indonesia

Received: 22 December 2017; accepted: 26 May 2018; published: 20 March 2019

Abstract: Objective: Carbohydrates, proteins, and fats are energy sources needed by the body for performing daily activities and generating primary energy substances. In women who have undergone menopause, the function of thyroid hormone in their body begins to decline and thus affects the ability of the body to produce energy. The purpose of this study was to determine the correlation between the intakes of carbohydrates, proteins, and fats and random blood sugar levels in menopausal women.

Methods: This study was a correlational analytical research with a cross-sectional design, which was conducted in 72 menopausa women recruited by the purposive sampling technique. In this study, a 24-hour food recall form was used, and randomized blood sugar levels were measured using a glucometer. The analysis of the data was performed using a Pearson product moment and multiple linear regression.

Results: Carbohydrates and fats together affected random blood sugar levels with an $F$-value of 25.810 and a $p$-value of 0.000 . Meanwhile, adjusted $R^{2}$ showed the value of 0.411 , indicating that the difference in the intake of carbohydrates and fats together affected random blood sugar levels by $41.1 \%$.

Conclusions: Intake of carbohydrates and fats affected random blood sugar levels, whereas the rest were influenced by other factors, and protein intake was unrelated to random blood sugar levels in menopausal women.

Keywords: carbohydrate intake • fats • menopausal women • protein • random blood sugar levels

(c) Shanxi Medical Periodical Press.

\section{Introduction}

Diabetes mellitus (DM) is a major health problem in the world. WHO estimated that more than 346 million people worldwide suffer from DM. ${ }^{1}$ In women, DM is a leading cause of death due to non-communicable diseases. ${ }^{2}$ Obesity, high-calorie diet, and lack of physical activity and exercises are some contributing factors to DM.
Women, especially in the postmenopausal period, have decreased thyroid and leptin hormones, which results in decreased basal metabolic rate and fat metabolism, causing a tendency to obesity. ${ }^{3}$

People with obesity often have decreased functions of insulin, which causes the disruption of blood sugar metabolism, resulting in increased blood sugar levels. Blood sugar levels are elevated in untreated DM. An

How to cite this article: Suniyadewi NW, Pinatih GNI. Correlation between intakes of carbohydrates, protein, and fat with random blood sugar levels in menopausal women. Front Nurs. 2019; 1: xx-xx. 
elevated random blood sugar level of $\geq 200 \mathrm{mg} / \mathrm{dl}$, along with the symptoms of polyuria, polydipsia, polyphagia, and unexplained weight loss are diagnostic criteria for DM. ${ }^{1}$ Therefore, the level of random blood sugar is one of the earliest indicators to detect the possibility of DM. However, for further detection, two or more blood sugar tests, either fasting blood sugar or blood sugar before or 2 hours after a meal with abnormal value, are still required. Based on a preliminary study conducted in menopausal women, it was shown that $58 \%$ of these women had random blood sugar levels of $\geq 200 \mathrm{mg} / \mathrm{dl}$. It was also indicated that these women had an average carbohydrate and fat intake, which exceeded their daily needs. This study aimed to determine the correlation between the intakes of carbohydrates, proteins, and fats and random blood sugar levels in menopausal women.

\section{Materials and methods}

This study used an analytical cross-sectional design and was conducted in the work area of Public Health Centers III in North Denpasar, Bali. A total of 72 menopausal women were included in this study. The inclusion criteria are as follows: willing to be a respondent, do not have DM, hypothyroidism or hyperthyroidism, menopause not caused by tumors, cancer, estrogen hormone therapy, and has no history of hysterectomy. They were recruited by the consecutive sampling technique. To measure the intakes of carbohydrates, proteins, and fats, a form of 24-hour food recall for household use was used. ${ }^{4}$ The data were retrospectively collected. The respondents were requested to write on the 24-hour recall form on Monday to assess the food intake on Sunday, on Wednesday for Tuesday's intake, and on Saturday for Friday's intake. The intakes were converted into grams by using the Nutrisurvey program, 2007 version. Weitgasser et al. ${ }^{5}$ reported that random glucose levels could be measured in milligrams per deciliter (mg/dl) by using an Essay Touch glucometer with a sensitivity of $70 \%$ and a specificity of $90 \%$. A capillary blood sugar examination was randomly done once without considering the mealtimes.

In this study, the data were analyzed using a bivariate analysis of Pearson product moment and a multivariate analysis of multiple regression tests. This study was approved by the Research Ethics Committee of the Faculty of Medicine, Udayana University and Sanglah Denpasar Hospital of number 204/UN.14.2/Litbang/2015 dated on February 18, 2015.

\section{Results}

All respondents $(n=72)$ participated in this study well. The majority were $60-74$ years $(88.90 \%)$ and worked as a housewife (86.10\%).
In Table 1, it can be seen that the average intake of carbohydrates, proteins, and fats of the 72 respondents in 3 days is lower than the average daily nutritional intake of women aged $65-80$ years. Based on the average level of blood sugar, the respondents are included in the category of uncertain DM.

In Table 2, it can be seen that the results of the bivariate analysis with Pearson product moment showed a strong, positive, and significant correlation between carbohydrate intake and random blood sugar levels with $r=0.647$. Moreover, there was also a weak, positive, and significant correlation between fat intake and random blood sugar levels with $r=0.264$. However, there was no correlation between protein intake and random blood sugar levels.

Table 3 shows that carbohydrate and fat intakes are associated with blood sugar levels in menopausal women with a $p$-value of 0.000 and an adjusted $R^{2}$ of 0.411 . This means that $41.10 \%$ increase in blood sugar levels is affected by carbohydrate and fat intakes, whereas the rest is affected by other factors. Similarly, the $t$-value of each variable indicates that carbohydrate and fat intakes are associated with random blood sugar levels.

\begin{tabular}{lcccc}
\hline Scores & $\begin{array}{c}\text { Carbohydrates } \\
(\mathrm{g})\end{array}$ & $\begin{array}{c}\text { Proteins } \\
(\mathrm{g})\end{array}$ & Fats $(\mathrm{g})$ & $\begin{array}{c}\text { Random blood } \\
\text { sugar }(\mathrm{g} / \mathrm{dl})\end{array}$ \\
\hline \hline Mean & 230.67 & 38.70 & 24.04 & 183.50 \\
Minimum & 93.00 & 15.70 & 11.72 & 96.00 \\
Maximum & 418.50 & 76.63 & 39.19 & 271.00 \\
SD & 68.27 & 1.12 & 6.10 & 4.30 \\
\hline
\end{tabular}

Table 1. Average intake of carbohydrates, proteins, and fats and blood sugar levels.

\begin{tabular}{lcc}
\hline \multirow{2}{*}{ Variables } & \multicolumn{2}{c}{ Random glucose level } \\
\cline { 2 - 3 } & $P$ & $r$ \\
\hline \hline Carbohydrate intake & 0.000 & 0.647 \\
Protein intake & 0.576 & -0.670 \\
Fat intake & 0.025 & 0.264 \\
\hline
\end{tabular}

Table 2. Bivariate correlation analysis between the intake of carbohydrates, proteins, and fats and random blood sugar levels.

\begin{tabular}{lccccc}
\hline Variables & $t$ & $P$ & $\begin{array}{c}\text { Adjusted } \\
R^{2}\end{array}$ & $F$ & $P$ \\
\hline \hline Carbohydrate intake & 6.080 & 0.000 & 0.411 & 25.81 & 0.000 \\
Fat intake & 2.262 & 0.027 & & & \\
\hline
\end{tabular}

Table 3. Multivariate analysis between the intake of carbohydrates, proteins, and fats and random blood sugar levels. 


\section{Discussion}

This study shows that there is a correlation between carbohydrate and fat intakes and random blood sugar levels in menopausal women, and only protein intake is not correlated. Carbohydrate intake can increase random blood sugar levels, and according to Sudoyo, ${ }^{6}$ it occurs because carbohydrates are converted into disaccharides that are broken down into monosaccharides, i.e., glucose, fructose, and galactose. Glucose and galactose are absorbed faster than fructose, and hence they can directly increase blood sugar levels, and along with the fat intake, they can also indirectly lead to obesity. The results of absorption of the monosaccharide, if not used by the body, circulates in the blood and are gradually stored in the liver and muscle tissues in the form of glycogen by the insulin. ${ }^{7}$ It is because the rest of the unused carbohydrates are quickly converted to fatty acids and glycerol and are eventually stored as triglycerides in the adipose tissues. The excessive intake of carbohydrate that is not balanced with energy consumption will be stored as fat tissue that can lead to obesity. ${ }^{8}$

In line with carbohydrate intake, fat intake is also associated with random blood sugar levels. It is because excessive fat intake can increase the risk of obesity. In obese individuals, increased fat intake can aggravate the condition and may increase the risk of metabolic syndrome; one of which is type $2 \mathrm{DM}$. In obese individuals, there is a risk of an inflammatory response due to the accumulation of trans fats. Trans fats can quickly cause a person to gain weight. A person who has excess body weight has a greater risk of insulin resistance since the fat interferes with the body's ability to use insulin. In menopausal women, the leptin produced by the pituitary gland is decreasing. A decreased level of leptin will decrease the rate of fat metabolism and make the hypothalamus function abnormal, and this causes a state of hyperphagia. Meanwhile, the amount of insulin will increase, which causes the occurrence of hyperinsulinemia. However, in

\section{References}

1. The Indonesian Society of Endocrinology [PERKENI]. Consensus of Management of Dyslipidemia in Indonesia. Jakarta: Pusat Penerbitan IImu Penyakit Dalam Fakultas Kedokteran UI. 2011 (in Indonesian).

2. Basic Health Research. Agency for Health Research and Development. Jakarta: Kemenkes RI. 2007 (in Indonesian).

3. Thurston RC, Khan UI, Wang DD, et al. Burden of subclinical cardiovascular disease in "metabolically benign" and "at-risk" overweight and obese this state, the insulin cannot work well due to its resistance caused by the buildup of fat tissue that causes increased levels of glucose in the blood. ${ }^{9}$

According to Dedi, ${ }^{10}$ premenstrual syndrome and postmenopause make the body fat to be easily accumulated due to hormonal process and hence women are at risk of increased blood sugar levels that lead to type 2 DM. If hyperglycemia occurs in prolonged time and exceeds $200 \mathrm{mg} / \mathrm{dl}$ and is worsened by the presence of insulin resistance due to obesity and/or menopause, there will be an increase in $\mathrm{HbA} 1 \mathrm{c}$, which causes someone to positively suffer from DM. ${ }^{11}$

Based on the results of this study, it is indicated that only protein variable is unrelated to random blood sugar levels. In a study by Indriasari, ${ }^{12}$ which investigated the relationship between diet and blood sugar levels in outpatients with type $2 \mathrm{DM}$, the $p$-value of the protein intake was 0.162 , indicating that there was no correlation between protein intake and blood sugar levels. It occurs because the primary function of protein is to assist the process of growth and replace damaged cells. Furthermore, protein stays longer in the stomach since it is not hydrolyzed by the gas. This condition is beneficial to prevent the occurrence of hunger and overeating to prevent from obesity. In the Atkins diet, the intake of proteins should be increased, whereas the intake of carbohydrates should be decreased. ${ }^{13}$

\section{Conclusions}

The variables that were evident to be significantly correlated with random blood sugar levels in menopausal women include carbohydrate and fat intake. On the contrary, protein intake was unrelated to the random blood sugar level.

\section{Conflicts of interest}

All contributing authors declare no conflicts of interest. women: the study of Women's Health Across Nation (SWAN). Atherosclerosis. 2007;217:179-186.

4. Arisman. Course Book of Nutrition Science in the Life Cycle. Jakarta: EGC. 2009 (in Indonesian).

5. Weitgasser R, Hofmann M, Gappmayer B, Garstenauer C. New, small, fast acting blood glucose meters - an analytical laboratory evaluation. Swiss Med Wkly. 2007;137:536-540.

6. Sudoyo. In: Jilid V III, ed. Course Book on Internal Diseases. Jakarta: Interna Publishing. 2007 (in Indonesian). 
7. Department of Nutrition and Public Health, FKM UI. Nutrition and Public Health. Jakarta: Raja Grafindo Perkasa. 2007 (in Indonesian).

8. Jenkins DJ, Kendall CW, Augustin LS, et al. Glycemic index: overview of implications in health and disease. Am J Clin Nutr. 2002;76:266S-273S.

9. Pamela R. Overweight and Obesity as Risks of Degenerative Diseases. 2011. www.suyotohospital. com (in Indonesian).

10. Dedi I. (2010). Prevalence and Risk Factors of Type 2 Diabetes Mellitus Incidence in Urban Areas in
Indonesia. Analisa Data Sekunder Riskesdas. 2007 (in Indonesian).

11. Adam. Obesity and Metabolic Syndrome. Bandung: FK Universitas Pajajaran. 2006 (in Indonesian).

12. Indriasari. Relationship between Diet and Blood Sugar Level in Outpatients with Type 2 DM in the Work Area of Public Health Centers in Makassar City. Program Studi IImu Gizi Fakultas Kesehatan Masyarakat Universitas Hasanuddin. 2014 (in Indonesian).

13. Atkins SS, Williams LD. Sourcebook in Expressive Arts Therapy. Boone, NC: Parkway. 2007. 